\title{
Cycloastragenol Is a Potent Telomerase Activator in Neuronal Cells: Implications for Depression Management
}

\author{
Fanny C.F. Ip ${ }^{\mathrm{a}-\mathrm{d}}$ Yu Pong $\mathrm{Ng}^{\mathrm{a}-\mathrm{d}}$ H.J. An ${ }^{\mathrm{a}}$ Ying Dai ${ }^{\mathrm{a}-\mathrm{c}}$ Hai Hong Pang ${ }^{\mathrm{a}}$ \\ Yue Qing $\mathrm{Hu}^{a}$ Allison C. Chin ${ }^{\mathrm{e}}$ Calvin B. Harleye, ${ }^{\mathrm{f}}$ Yung Hou Wong ${ }^{\mathrm{a}-\mathrm{d}}$ \\ Nancy Y. Ip ${ }^{a-d}$ \\ ${ }^{a}$ Division of Life Science, ${ }^{b}$ Molecular Neuroscience Center, ${ }^{c}$ Biotechnology Research \\ Institute, and d State Key Laboratory of Molecular Neuroscience, The Hong Kong University of \\ Science and Technology, Hong Kong, China; ${ }^{\mathrm{e}}$ Geron Corporation, and ${ }^{\mathrm{f}}$ Telome Health Inc., \\ Menlo Park, Calif., USA
}

Key Words

CAMP response element binding · NGF · Astragalus membranaceus · Saponin · Telomere

Telomerase reverse transcriptase

\section{Abstract}

Cycloastragenol (CAG) is an aglycone of astragaloside IV. It was first identified when screening Astragalus membranaceus extracts for active ingredients with antiaging properties. The present study demonstrates that CAG stimulates telomerase activity and cell proliferation in human neonatal keratinocytes. In particular, CAG promotes scratch wound closure of human neonatal keratinocyte monolayers in vitro. The distinct telomerase-activating property of CAG prompted evaluation of its potential application in the treatment of neurological disorders. Accordingly, CAG induced telomerase activity and CAMP response element binding (CREB) activation in PC12 cells and primary neurons. Blockade of CREB expression in neuronal cells by RNA interference reduced basal telomerase activity, and CAG was no longer efficacious in increasing telomerase activity. CAG treatment not only induced the expression of $b c l 2$, a CREB-regulated gene, but also the expression of telomerase reverse transcriptase in primary cortical neurons. Interestingly, oral administration of CAG for 7 days attenuated depression-like behavior in experimental mice. In conclusion, CAG stimulates telomerase activity in human neonatal keratinocytes and rat neuronal cells, and induces CREB activation followed by tert and bcl 2 expression. Furthermore, CAG may have a novel therapeutic role in depression. 


\section{Introduction}

Telomerase is an RNA-dependent DNA polymerase complex that contains a telomerase reverse transcriptase (TERT) and telomerase RNA [1-3]. TERT utilizes telomerase RNA as a template to synthesize telomeric repeats at the end of a chromosome, which is essential for protection against cellular senescence induced by critical telomere shortening [1-6]. Although telomerase is linked to cell immortalization and cancer development, emerging evidence suggests its importance in brain development and age-related neurodegenerative disorders.

There are high levels of telomerase expression and activity in neural stem cells and progenitors, which decrease when cells differentiate or die [7-11]. Although telomerase activity in the nervous system is high in the prenatal brain, it decreases to undetectable levels in adults $[4,5,8,12,13]$. However, accumulating evidence suggests that telomerase activity and expression are important for adult neurogenesis in the subventricular zone and olfactory bulb [8]. Aged telomerase RNA-knockout mice with telomere dysfunction exhibit memory deficits $[13,14]$. The telomere length of peripheral blood lymphocytes has recently been proposed to be a biomarker of individuals suffering from chronic stress, depression, schizophrenia, and pathological cognitive decline as observed in Alzheimer's disease and dementias [15-18]. These findings demonstrate that psychological disorders and neurodegenerative diseases are related to telomere shortening. In addition to its conventional function in telomere maintenance, TERT may have a neuroprotective function against apoptosis induced by DNA damage, trophic factor withdrawal, ischemia, glutamate, and amyloid peptide [12, 19-27]. Therefore, the reported functions of telomerase and TERT in normal and diseased brains have attracted substantial interest in understanding their roles in the nervous system.

We first identified cycloastragenol $(\mathrm{CAG}$, molecular weight $=490.72)$ when screening natural compounds from Astragalus membranaceus extracts for antiaging properties that promote telomerase activity and wound gap closure. This aglycone of astragaloside IV effectively enhances the antiviral response in human CD8+ T-lymphocytes through its distinct telomerase-promoting activity [28]. Furthermore, we demonstrated that CAG stimulates the phosphorylation of extracellular signal-regulated proteins in multiple cell lines and is absorbed via the intestinal epithelium $[29,30]$. Importantly, we have evaluated the pharmacological effects of CAG in neuronal cells as well as its effects on depression-like behaviors in mice.

\section{Materials and Methods}

Synthesis of CAG

CAG (Registry No. 84605-18-5; fig. 1a) is a natural saponin of the Astragalus species found in small amounts [31, 32]. CAG used in the present study was synthesized by acid hydrolysis of its glycoside astragaloside IV (Sigma-Aldrich, USA) as described previously [33]. The identity of CAG was determined and confirmed by ${ }^{1} \mathrm{H}-\mathrm{NMR},{ }^{13} \mathrm{C}-\mathrm{NMR}$, and mass spectrometry. The purity exceeded $99 \%$. Stock solution was prepared in dimethyl sulfoxide (DMSO; Sigma-Aldrich) and stored at $-80^{\circ} \mathrm{C}$.

\section{Animals}

All experiments were carried out on male ICR mice weighing 20-25 g (Bltw:CD1; BioLASCO, Taiwan) maintained in the Animal and Plant Care Facility of The Hong Kong University of Science and Technology (HKUST). This study was approved by the Animal Ethics Committee of the HKUST and conducted in accordance with the Code of Practice for Care and Use of Animals for Experimental Purposes.

\section{Cell Cultures}

PC12 cells were obtained from the American Type Culture Collection and cultured as described previously [34]. Primary cortical and hippocampal neuron cultures were prepared from embryonic day 18 rats as described previously [35]. Primary neurons were plated on culture dishes coated with poly-D-lysine (Sigma- 


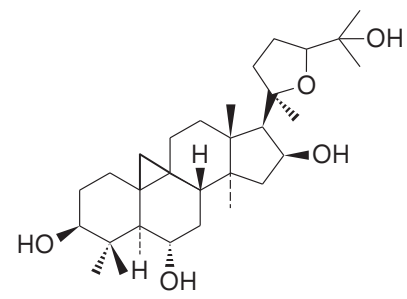

a
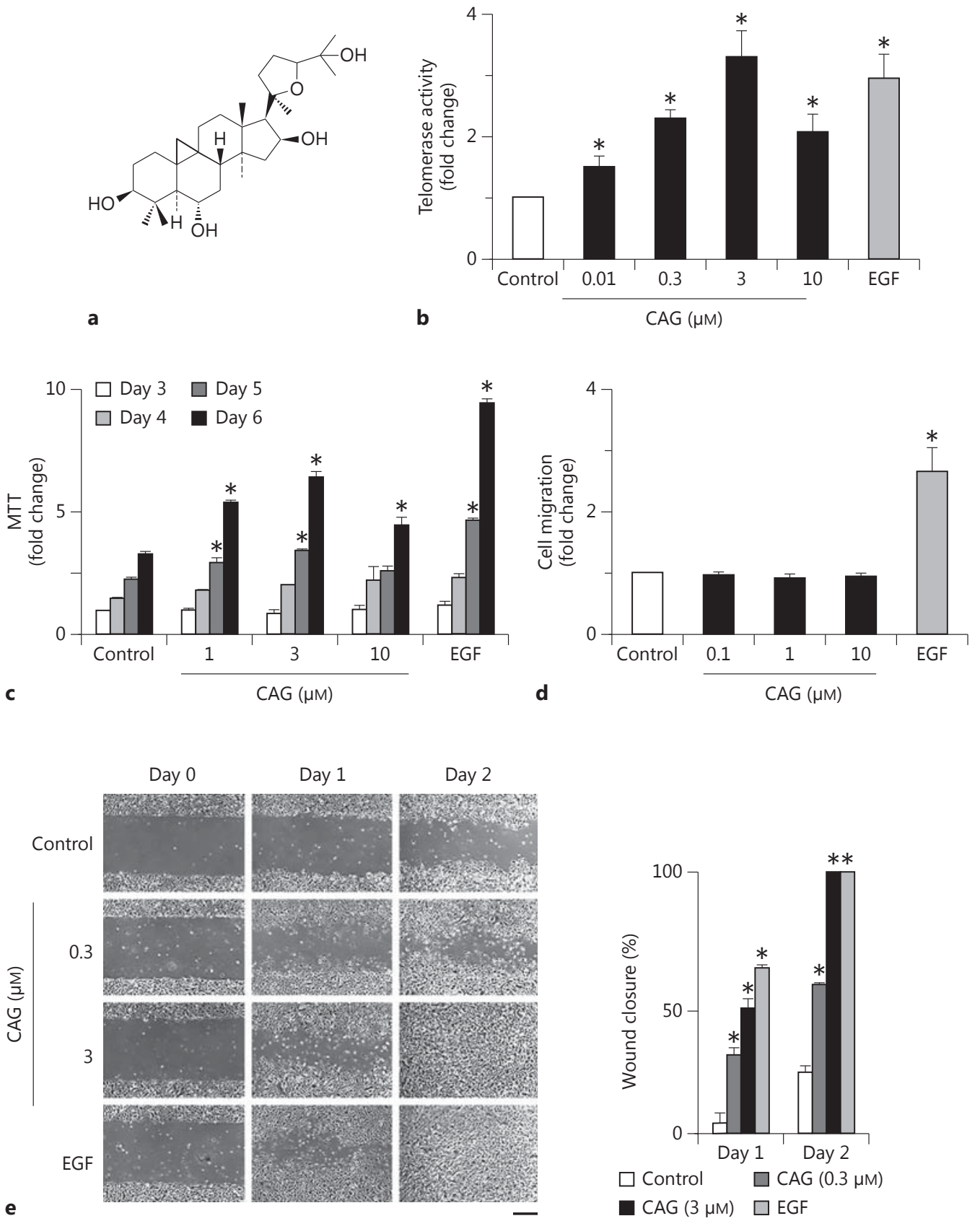

Fig. 1. CAG stimulates telomerase activity and facilitates in vitro scratch wound closure in HEKn cells. a Chemical structure of CAG $\left(\mathrm{C}_{30} \mathrm{H}_{50} \mathrm{O}_{5}\right.$, molecular weight: 490.72). b HEKn cells were treated with CAG at 0.01-10 $\mu \mathrm{M}$ for $24 \mathrm{~h}$. Telomerase activity in cell lysates was measured by RQ-TRAP assay. c MTT assay was performed in the HEKn cultures for 4 consecutive days after 3 days of CAG treatment. d HEKn cells were seeded in membrane inserts and incubated in CAG $(0.1-10 \mu \mathrm{M})$ or EGF (50 ng/ml). A cell migration assay was performed after $24 \mathrm{~h}$. e Scratched HEKn monolayers were treated with 0.3 or $3 \mu \mathrm{M}$ CAG and 0.3\% DMSO (Control) for 2 days. EGF ( $50 \mathrm{ng} / \mathrm{ml}$ ) was used as a positive control. Three consecutive fields were taken for 2 days. Results from representative experiments are shown. Wound closure is presented as the percentage of wound closure following various treatments. Values are expressed as the fold change relative to the control and represent the means \pm SEM of three separate experiments. ${ }^{*} \mathrm{p}<0.05$. Scale bar $=0.5 \mathrm{~mm}$. 
Table 1. Primers used for RT-PCR and qPCR

\begin{tabular}{lll}
\hline Gene & Forward primers $\left(5^{\prime}-3^{\prime}\right)$ & Reverse primers $\left(5^{\prime}-3^{\prime}\right)$ \\
\hline$t e r t$ & CAAGCTATCCCTGCAGGAACTGAT & ACTCTGAGTGAAACACTGGGTCTG \\
$b c l 2$ & ATAACCGGGAGATCGTGATG & CAGGCTGGAAGGAGAAGATG \\
$n g f$ & CAACAGGACTCACAGGAGCA & GTCCGTGGCTGTGGTCTTAT \\
$b d n f$ & GGCCCAACGAAGAAAACC & AGCATCACCCGGGAAGTG \\
$n t 3$ & GGGGGATTGATGACAAACAC & ACAAGGCACACACACAGGAA \\
$g a p d h$ & TGATGCTGGTGCTGAGTATGTCGTG & TCCTTGGAGGCCATGTAGGCCAT \\
\hline
\end{tabular}

Aldrich). Cultures were maintained in Neurobasal medium containing B27 supplement (Invitrogen, USA), penicillin $(50 \mathrm{U} / \mathrm{ml})$, and streptomycin $(100 \mu \mathrm{g} / \mathrm{ml})$.

\section{HEKn Cell Proliferation, Migration, and Wound Closure Assays}

HEKn cells were incubated with CAG for the indicated time intervals. An MTT [3-(4, 5-dimethylthiazol-2-yl)-2,5-diphenyltetrazolium bromide] assay was performed to monitor the cell proliferation of the treated cultures (USB, USA). A cell migration assay was performed according to the manufacturer's instructions (Cell BioLabs, USA).

For wound closure assays, a bisecting scratch was made with a sterile p1000 micropipette tip onto a HEKn cell monolayer. Cellular debris was removed by rinsing twice with phosphate-buffered saline. After $24 \mathrm{~h}$ of incubation in normal growth medium, the cells were treated with CAG for 2 days. The medium and drugs were replenished daily for the duration of the assay. Scratch wound closure was examined daily. Images of the gap were captured by a CCD camera attached to an inverted microscope (Nikon, USA), and the gap width was quantified using ImageJ (http://rsbweb.nih.gov/ij/).

\section{Telomerase Activity Assay}

HEKn cells (population doubling time: 3-6 days), PC12 cells (passage No.: 12-18), cultured primary cortical, and hippocampal neurons [12 days in vitro (DIV)] were treated with CAG for $24 \mathrm{~h}$. Total cell lysates were then collected by using the lysis buffer provided in the real-time quantitative telomeric repeat amplification protocol (RQ-TRAP) assay kit (Allied Biotech, USA). Telomerase activity was determined by using an ABI Prism 7000 according to the manufacturer's instructions (Applied Biosystems, USA).

\section{RT-PCR and Quantitative RT-PCR}

Total RNA extraction, cDNA synthesis, and Southern blot analysis were performed as described previously [36]. The total RNA of primary cortical neurons (12 DIV) or mouse cortices was isolated using a commercial kit (Qiagen, Germany). cDNA was synthesized from $5 \mu \mathrm{g}$ total RNA using oligo-dT primers according to the manufacturer's protocol (Invitrogen). One tenth of the cDNA mixture was used as the template for the subsequent PCR. The primer sequences are listed in table 1. PCR products were separated on a 1.5\% agarose gel, and Southern blot analysis was performed to detect the tert expression. Southern blots were quantified using ImageJ (http://rsbweb.nih.gov/ij/).

For quantitative PCR (qPCR), the target gene expression was quantified using a Power SYBR Green PCR master mix kit in a 7500 Fast Real-time PCR system according to the manufacturer's instructions (Applied Biosystems). The specificity of the SYBR Green PCR signal was confirmed by melting curve analysis. In each experiment, glyceraldehyde 3-phosphate dehydrogenase (gapdh) mRNA was amplified as the control standard.

\section{Western Blot Analysis}

Cells in treated cultures were harvested and lysed with RIPA buffer containing $150 \mathrm{~mm} \mathrm{NaCl}, 1 \%$ Nonidet P-40, 1 mM EDTA, 0.5\% deoxycholic acid, $2 \mu \mathrm{g} / \mathrm{ml}$ aprotinin, $1 \mathrm{~mm}$ PMSF, $5 \mathrm{~mm}$ benzamidine, 1 mm sodium orthovanadate, and $10 \mu \mathrm{g} / \mathrm{ml}$ soybean trypsin inhibitor in $50 \mathrm{~mm}$ Tris buffer (pH 7.4). The protein concentration was determined by using a Bio-Rad protein assay kit (Hercules, USA). Equal quantities of protein were resolved by SDS-PAGE and transferred to nitrocellulose membranes. Membranes were blocked in TBST with $5 \%$ nonfat dry milk for $1 \mathrm{~h}$ and then incubated with primary antibodies overnight at $4{ }^{\circ} \mathrm{C}$. Primary antibodies against phosphoserine (Ser) 133 cAMP response element binding (CREB) and total CREB were purchased from Cell Signaling Technology (USA). Anti- $\alpha$-tubulin antibody was from Sigma-Aldrich. The blots were 
washed with TBST and incubated with anti-rabbit or anti-mouse horseradish peroxidase-conjugated secondary antibody (Cell Signaling Technology). The proteins were detected by an enhanced chemiluminescence detection system (GE Healthcare, UK).

\section{Small Interfering RNA CREB Knockdown}

PC12 cells were transfected with CREB small interfering RNA (siRNA) by using Oligofectamine Transfection Reagent (Invitrogen) according to the manufacturer's instructions. The sense sequence of the CREB siRNA oligonucleotide was 5'-GGAGUCUGUGGAUAGUGUAACUGAU-3'; an siRNA oligonucleotide targeting the luciferase RNA, 5'-CGUACGCGGAAUACUUCGATT-3' (sense sequence), was used as a control.

Behavioral Tests

Mice were administered CAG $100 \mathrm{mg} / \mathrm{kg}$, or water by oral gavage, or imipramine $15 \mathrm{mg} / \mathrm{kg}$ (SigmaAldrich), a currently used tricyclic antidepressant, by intraperitoneal injection for 7 days as well as 45 min before testing. The forced swim test was performed as described previously $[37,38]$, by placing a mouse in a glass cylinder (height: $30 \mathrm{~cm}$, diameter: $15 \mathrm{~cm}$ ) filled with water to a depth of $12 \mathrm{~cm}$. Mice were tested in the cylinder for $6 \mathrm{~min}$. The water was changed before testing another animal. All test sessions were recorded by a video camera positioned in front of the glass cylinder. Depression-like behavior was determined by observing the immobility of the mouse, where immobility is defined as when a mouse floats passively in the water with minimal movement to keep its head above the water. The total period of immobility during the last 4 min of the test session was determined.

The open-field test was performed as described previously to examine general locomotor activity in mice [39]. The open-field apparatus comprised an open-top black Plexiglas box $(50 \times 50 \times 40 \mathrm{~cm})$. A mouse was placed in the center of the apparatus to initiate a 20-min test session. Spontaneous locomotor activity was recorded and analyzed using Ethovision XT (Noldus Information Technology, USA). The open-field arena was divided into a $4 \times 4$ grid of squares. The total distance travelled, the total time the mouse entered the central four squares (i.e., the central zone), and the total time the mouse stayed in the outer 12 squares (i.e., the peripheral zone) were measured by the software.

Statistical Analysis

Each experiment was repeated at least three times. The significance of differences was tested by Student's t test or one-way ANOVA where appropriate. The level of significance was set at $\mathrm{p}<0.05$.

\section{Results}

\section{CAG Promotes in vitro Scratch Wound Closure}

CAG is an aglycone of astragaloside IV (fig. 1a). CAG treatment enhanced telomerase activity in HEKn cells (fig. 1b). CAG ( $3 \mu \mathrm{M}$ ) induced the greatest telomerase activation, similar to that of epidermal growth factor (EGF, $50 \mathrm{ng} / \mathrm{ml}$ ). To determine whether CAG exerts a wound closure effect, HEKn cells were incubated with CAG and an MTT assay was performed to monitor the cell growth. Treatment with $3 \mu \mathrm{M}$ CAG for 6 days doubled the cell growth compared to the vehicle control (fig. 1c). However, CAG did not induce HEKn cell migration at any concentration tested (fig. 1d).

The effect of CAG on wound closure was further examined by treating scratched monolayers of HEKn cells for 2 days. Similarly, both 0.3 and $3 \mu \mathrm{M}$ CAG improved the recovery of monolayers compared to cells treated with vehicle alone (fig. 1e). Interestingly, the scratch wound closure effect of CAG was comparable to that of EGF $(50 \mathrm{ng} / \mathrm{ml})$ after the 2-day treatment.

\section{CAG Induces Telomerase Activity in Neuronal Cells via CREB Activation}

To assess the effect of CAG in the nervous system, we first examined if it promoted telomerase activity in neuronal cells. PC12 cells and primary cortical and hippocampal neuron cultures were treated with CAG for $24 \mathrm{~h}$. An RQ-TRAP assay was performed to measure telomerase activity in the cell lysates. Compared to control cells exposed to $0.3 \%$ DMSO, $1-3 \mu \mathrm{M}$ 

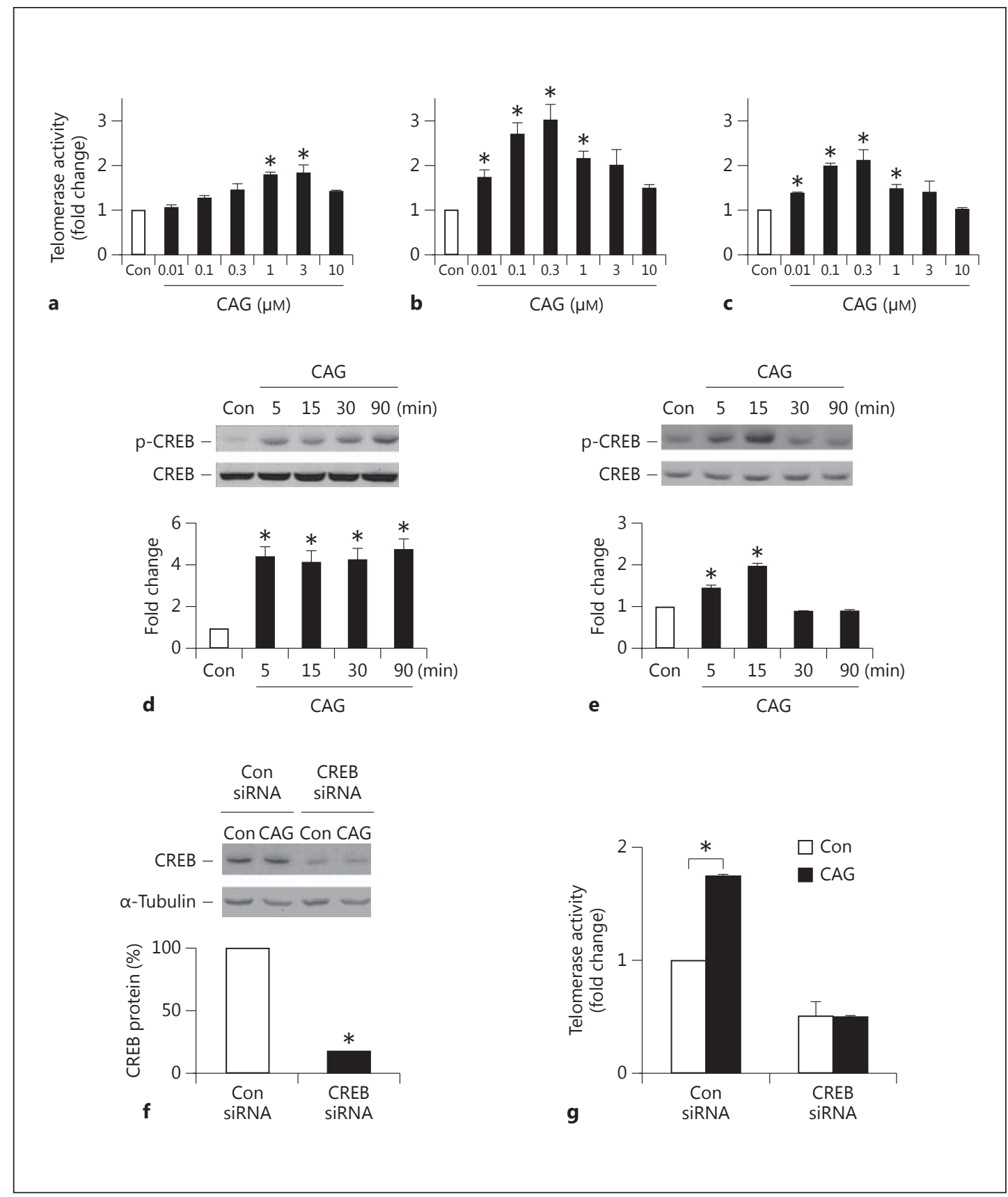

Ip et al.: Cycloastragenol Is a Potent Telomerase Activator in Neuronal Cells: Implications for Depression Management

Fig. 2. CAG induces telomerase activity via CREB activation in neuronal cells. PC12 cells (a), primary cortical neurons (b), and hippocampal neurons (c) were treated with 0.01-10 $\mu \mathrm{M}$ CAG for $24 \mathrm{~h}$. DMSO (0.3\%) was used as a control (Con). Total cell lysates were collected for RQ-TRAP assay. PC12 cells and cortical neurons were treated with $0.3 \mu \mathrm{M}$ CAG for 5-90 min, followed by Western blot analyses of CREB (d, e). Values are expressed as the fold change relative to the vehicle control and represent the means \pm SEM of three separate experiments. ${ }^{*} \mathrm{p}<0.05$. $\mathbf{f}$ CREB protein expression was examined in PC12 cells transfected with control and CREB siRNAs. g CAG-induced telomerase activity was examined in PC12 cells transfected with CREB siRNA by RQ-TRAP assay. Values are expressed as the fold change relative to DMSO-treated cells transfected with control siRNA and represent the means \pm SEM of three separate experiments. ${ }^{*} \mathrm{p}<0.05$. 

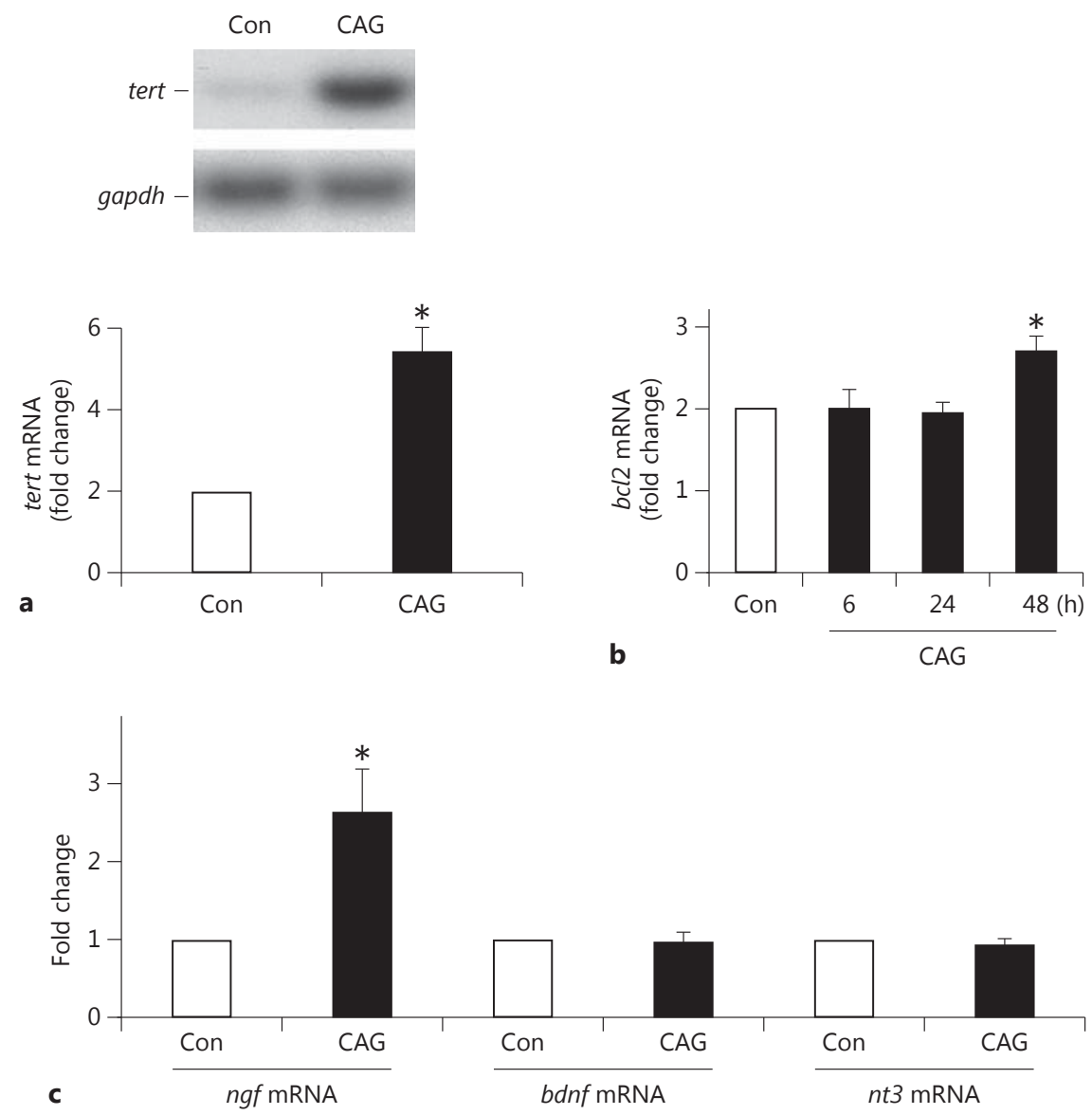

Fig. 3. CAG induces tert and prosurvival gene expression. Primary cortical neurons were treated with $3 \mu \mathrm{M}$ CAG for 6 h. Total RNA was isolated for qPCR; gapdh mRNA expression was included as an equal-loading control. The identities of the PCR products were confirmed by Southern blotting; a representative blot is shown in a. The relative expression of tert mRNA to DMSO-treated cells is shown. Values represent the results of three separate experiments. ${ }^{*} \mathrm{p}<0.05$. Primary cortical neurons were treated with $3 \mu \mathrm{M}$ CAG for 6-48 h. Target mRNAs were then examined by real-time PCR with specific primers for bcl2 (b). Mice were treated with $100 \mathrm{mg} / \mathrm{kg}$ CAG or water daily for 7 days. Total RNA was isolated from the cortex of the mice for the detection of $n g f, b d n f$, and $n t 3$ by real-time RT-PCR with specific primers (c). For qPCR, the expression of the target genes is presented as the fold change relative to the vehicle control after normalization to that of gapdh mRNA expression. Values represent the means \pm SEM of three separate experiments. ${ }^{*} \mathrm{p}<0.05$.

CAG treatment induced a significant ( $\sim$-fold) increase in telomerase activity in PC12 cells (fig. 2a). In addition, cultured primary neurons (12 DIV) treated with $0.01 \mu \mathrm{M}$ CAG exhibited significantly elevated telomerase activity (fig. $2 b, c)$. The greatest effect was observed in primary cortical and hippocampal neurons treated with 0.1-0.3 $\mu \mathrm{M}$ CAG. These results collectively suggest that CAG induces telomerase activation in a neuronal cell line and primary neurons.

The roles of CREB signaling in the regulation of brain development, adult neurogenesis, cognitive functions, and depression have recently been elucidated [40-43]. To further characterize the functions of CAG, we investigated its effect on CREB signaling in PC12 cells. CREB phosphorylation at Ser133 was detected in PC12 cells after a 5-min treatment with $0.3 \mu \mathrm{M}$ CAG, which was sustained up to 90 min (fig. 2d). More importantly, CREB phosphorylation 
was also induced in primary cortical neurons after a 15-min treatment with $0.3 \mu \mathrm{M}$ CAG (fig. 2e). Total CREB expression was unaltered by CAG in both cell types (fig. 2d, e). As CREB phosphorylation at Ser133 is strongly correlated with CREB activation [44, 45], the present results suggest that CAG induces CREB activation in neuronal cells. Thus, in order to determine if this CREB activation is responsible for the observed CAG-induced telomerase activities, the effect of CAG in CREB-deficient cells was examined. Suppression of CREB expression by RNA interference significantly reduced telomerase activity in PC12 cells (fig. 2f, g). This result indicates that both basal and CAG-induced activities are dependent on CREB expression.

\section{CAG Upregulates tert, bcl2, and ngf mRNA Expression}

TERT expression is closely associated with the regulation of telomerase activity [4-6]. Moreover, several lines of evidence suggest that TERT exhibits functions independent of its reverse transcriptase and telomerase RNA activities [5, 12, 20-27]. To further characterize the function of CAG in primary neuronal cells, primary cortical neuron cultures (12 DIV) were treated with $0.3 \mu \mathrm{M}$ CAG for $6 \mathrm{~h}$, and tert mRNA expression was examined. CAG treatment increased tert mRNA expression compared to the control cells (fig. 3a). These results suggest that elevated TERT expression may enhance telomerase activation in primary cortical neurons in response to CAG. Furthermore, cultured cortical neurons treated with CAG exhibited increased bcl2 mRNA expression (fig. $3 \mathrm{~b}$ ), suggesting that CAG may promote prosurvival signaling in neurons.

To demonstrate the in vivo efficacy of CAG, mice were administered CAG $(100 \mathrm{mg} / \mathrm{kg})$ or water by oral gavage for 7 days. Total RNA was collected from the mouse cerebral cortices for qPCR analysis of neurotrophin genes. Interestingly, while the levels of both BDNF and NT-3 remained unchanged, NGF expression was induced in the mouse cortex after 7 days of treatment (fig. 3c).

\section{CAG Reduces Depression-Like Behaviors in Mice}

Lifetime exposure to chronic stress or depression is associated with accelerated telomerase shortening, suggesting a possible link between depression and telomere maintenance $[15,18]$. In addition, CREB is postulated to play an indispensable role in antidepressant medications [40-42]. To elucidate the physiological significance of CAG in telomerase and CREB activation in neuronal cells, we determined if CAG exerts any antidepressant-like effect by using the forced swim test. There was no systemic toxicity following 7 days of CAG treatment, which is consistent with the reported toxicity profile of CAG [46]. Inducing despair in mice increases their immobility time (i.e., depression-like behavior) in the forced swim test [37, 38]. CAG or imipramine treatment for 7 days reduced the immobility time (fig. 4a). More importantly, CAG did not produce any psychostimulant effects as demonstrated in the open-field test (fig. 4b-d).

\section{Discussion}

Telomerase activators are proposed to increase the longevity of cells and are therefore actively being analyzed for antiaging strategies $[47,48]$. In accordance with our findings that CAG promotes the cellular functions of keratinocytes, the distinct telomerase-promoting activity of CAG has also been reported in human CD8+ T-lymphocytes; specifically, in its effects in enhancing their antiviral response against HIV [28]. Impaired cutaneous wound healing remains a major clinical problem in the elderly population as well as in patients with diabetes, hypertension, and obesity $[49,50]$. Although EGF exhibits a promising wound closure effect, its short half-life in the wound bed limits its widespread clinical usage. In the present study, treating scratched HEKn cell monolayers with CAG accelerated scratch wound 
Fig. 4. CAG decreases immobility duration in the forced swim test. Mice were administered CAG (100 mg/kg), water, or imipramine (Imi, $15 \mathrm{mg} / \mathrm{kg}$ ) daily for 7 days (a) before the forced swim test. The immobility duration (in seconds) is presented. Data represent the means \pm SEM $(n=50)$ of four independent experiments. $* \mathrm{p}<0.05$. Mice treated in a were subjected to the open-field test to examine their motor activity. The total distance travelled (b), duration in central zone (c), and duration in peripheral zone (d) within 20 min were recorded and presented as means \pm SEM. Data represent the results of four independent experiments.
Ip et al.: Cycloastragenol Is a Potent Telomerase Activator in Neuronal Cells: Implications for Depression Management

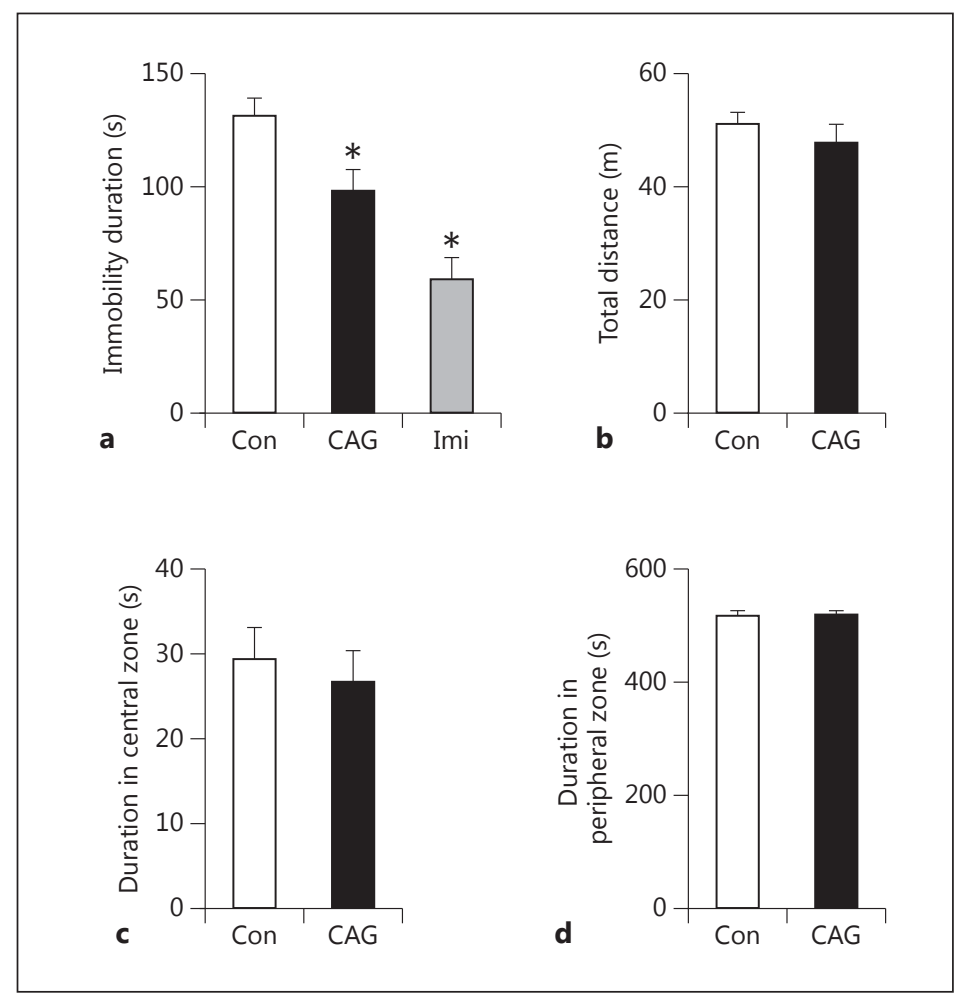

closure, which is consistent with a recent report on the wound closure effect of this molecule [51]. Although CAG did not affect HEKn cell migration, it induced the proliferation of HEKn cells, which can contribute to scratch wound closure. This finding has prompted us to investigate the possible therapeutic use of CAG in the treatment of acute and chronic cutaneous wounds in the future.

In addition, this study demonstrates for the first time that CAG exhibits antidepressantlike properties. CAG significantly reduced depression-like behaviors of mice in the forced swim test. CAG treatment also elicited significant telomerase and CREB activation in PC12 cells and primary neuronal cultures, which could account for its antidepressant effect. Accumulating evidence suggests that psychological and metabolic stress can lead to telomere dysfunction [15-18]. Stressed individuals usually exhibit reduced telomerase activity and accelerated telomere shortening compared to low-stress controls $[15,18]$. In particular, significant telomere erosion is reported in patients with psychiatric disorders such as schizophrenia, mood disorders, and pathological cognitive aging including Alzheimer's disease and dementias [15-18]. Taken together, these findings suggest that telomerase reconstitution (e.g., by CAG) is a potential strategy for retarding disease progression.

The functional relevance of telomerase reconstitution in the treatment of psychiatric disorders and cognitive dysfunction is further evidenced by the importance of telomerase activity in adult neurogenesis. Hippocampal neurogenesis is reported to be a target for the treatment of mental illnesses and cognitive dysfunction [8, 9, 52-54]. Adult neural progenitor cells exhibit telomerase activity, which is important for the maintenance of the neurogenic population in the central nervous system [8-11]. Therefore, further investigation of the effect of CAG on adult neurogenesis is warranted.

Although the role of CREB protein in the treatment of depression remains controversial, the CREB signaling pathway is undeniably important in the normal functions of and disease 
pathogenesis in the central nervous system. CREB is activated in response to synaptic stimulation, trophic factor treatment, and antidepressants; its activation subsequently modulates the transcription of genes containing cAMP-responsive elements in their promoters [40-45]. Interestingly, CAG induced CREB phosphorylation and CREB knockdown reduced both basal and CAG-induced telomerase activities in neuronal cells. Therefore, it would be of interest to further examine the direct relationship between CREB activation and telomerase activity.

Recent studies propose novel functions of telomerase and TERT in addition to their actions regarding telomere maintenance [7,19-27]. TERT coupled to Wnt/ $\beta$-catenin signaling mediates Wnt-dependent gene expression via chromatin remodeling [24]. Although telomerase activity in the brain decreases after embryonic development, TERT is still expressed in the mouse brain during the early postnatal stages though the telomerase RNA component is not detected. Moreover, cultured neurons exhibiting reduced TERT expression are more susceptible to cell death induced by amyloid-beta peptide, DNA damage, and oxygen-glucose deprivation, further supporting this hypothesis [7, 19-27]. This suggests that TERT may play active roles in controlling brain development through mechanisms other than telomere maintenance.

As discussed above, CAG exerts its telomerase-activating function by inducing TERT expression. CAG-induced TERT expression may also promote cell survival and regulate gene expression in the central nervous system. Accordingly, clinical depression may be attributable to impaired cell survival and cell death signaling pathways in neurons. Furthermore, prosurvival and neurotrophin signaling are implicated in antidepressant drug actions $[43,55$, 56]. The present finding that CAG can induce bcl2 mRNA expression in primary cortical neurons is consistent with previous studies showing that TERT regulates Bcl2 expression [26, $57,58]$. Moreover, treating mice with CAG for 7 days simultaneously increased $n g f$ mRNA in the cerebral cortex. Therefore, these findings further suggest that CAG exerts its antidepressant effect at least in part by promoting cell survival and neurotrophin signaling.

In conclusion, the results of the present study provide novel insights into the molecular mechanisms that mediate the actions of CAG. CAG stimulates telomerase activity in human neonatal keratinocytes and rat neuronal cells. It induces CREB activation followed by tert and bcl2 expression. Furthermore, oral administration of CAG attenuates the immobility behavior of mice in the forced swim test, thus demonstrating its therapeutic potential against depression. Designing therapies based on telomerase maintenance is therefore an attractive approach for treating neurodegenerative diseases and aging.

\section{Acknowledgements}

We would like to thank Venus W.S. Lee and Ka Chun Lok for their excellent technical assistance. The authors also thank Drs. Kim Wan Chan, Kwok On Lai, Ada Fu, and Amy Fu for helpful discussions. This study was supported in part by the Hong Kong Research Grants Council Theme-Based Research Scheme (T13-607/12R), the National Key Basic Research Program of China (2013CB530900), the Innovation and Technology Fund for State Key Laboratory (ITCPT/17-9), and the Shenzhen Peacock Plan.

\section{References}

1 Blackburn EH: Telomeres and telomerase: the means to the end (Nobel lecture). Angew Chem Int Ed Engl 2010;49:7405-7421.

-2 O'Sullivan RJ, Karlseder J: Telomeres: protecting chromosomes against genome instability. Nat Rev Mol Cell Biol 2010;11:171-181.

-3 Pinto AR, Li H, Nicholls C, Liu JP: Telomere protein complexes and interactions with telomerase in telomere maintenance. Front Biosci 2011;16:187-207.

-4 Prowse KR, Greider CW: Developmental and tissue-specific regulation of mouse telomerase and telomere length. Proc Natl Acad Sci USA 1995;92:4818-4822. 
5 Greenberg RA, Allsopp RC, Chin L, Morin GB, DePinho RA: Expression of mouse telomerase reverse transcriptase during development, differentiation and proliferation. Oncogene 1998;16:1723-1730.

6 Armstrong L, Lako M, Lincoln J, Cairns PM, Hole N: mTert expression correlates with telomerase activity during the differentiation of murine embryonic stem cells. Mech Dev 2000;97:109-116.

7 Kruk PA, Balajee AS, Rao KS, Boh VA: Telomere reduction and telomerase inactivation during neuronal cell differentiation. Biochem Biophys Res Commun 1996;224:487-492.

8 Caporaso GL, Lim DA, Alvarez-Buylla A, Chao MV: Telomerase activity in the subventricular zone of adult mice. Mol Cell Neurosci 2003;23:693-702.

-9 Cheng A, Shin-ya K, Wan R, Tang SC, Miura T, et al: Telomere protection mechanisms change during neurogenesis and neuronal maturation: newly generated neurons are hypersensitive to telomere and DNA damage. J Neurosci 2007;27:3722-3733.

10 Roy NS, Chandler-Militello D, Lu G, Wang S, Goldman SA: Retrovirally mediated telomerase immortalization of neural progenitor cells. Nat Protoc 2007;2:2815-2825.

-11 Ferrón SR, Marqués-Torrejón MA, Mira H, Flores I, Taylor K, et al: Telomere shortening in neural stem cells disrupts neuronal differentiation and neuritogenesis. J Neurosci 2009;29:14394-14407.

12 Fu W, Killen M, Culmsee C, Dhar S, Pandita TK, et al: The catalytic subunit of telomerase is expressed in developing brain neurons and serves a cell survival-promoting function. J Mol Neurosci 2000;14:3-15.

13 Lee J, Jo YS, Sung YH, Hwang IK, Kim H, et al: Telomerase deficiency affects normal brain functions in mice. Neurochem Res 2010;35:211-218.

14 Rolyan H, Scheffold A, Begus-Nahrmann Y, Heinrich A, Liss B, et al: Telomere shortening reduces Alzheimer's disease amyloid pathology in mice. Brain 2011;134:2044-2056.

15 Epel ES, Blackburn EH, Lin J, Dhabhar FS, Adler NE, et al: Accelerated telomere shortening in response to life stress. Proc Natl Acad Sci USA 2004;101:17312-17315.

16 Porton B, Delisi LE, Bertisch HC, Ji F, Gordon D, Li P, et al: Telomerase levels in schizophrenia: a preliminary study. Schizoph Res 2008;106:242-247.

17 Lukens JN, Van Deerlin V, Clark CM, Xie SX, Johnson FB: Comparisons of telomere lengths in peripheral blood and cerebellum in Alzheimer's disease. Alzheimers Dement 2009;5:463-469.

18 Wolkowitz OM, Epel ES, Reus VI, Mellon SH: Depression gets old fast: do stress and depression accelerate cell aging? Depress Anxiety 2010;27:327-338.

19 Fu W, Begley JG, Killen MW, Mattson MP: Anti-apoptotic role of telomerase in pheochomocytoma cells. J Biol Chem 1999;274:7264-7271.

-20 Zhu H, Fu W, Mattson MP: The catalytic subunit of telomerase protects neurons against amyloid beta-peptideinduced apoptosis. J Neurochem 2000;75:117-124.

21 Lu C, Fu W, Mattson MP: Telomerase protects developing neurons against DNA damage-induced cell death. Brain Res Dev Brain Res 2001;131:167-171.

22 Kang HJ, Choi YS, Hong SB, Kim KW, Woo RS, et al: Ectopic expression of the catalytic subunit of telomerase protects against brain injury resulting from ischemia and NMDA-induced neurotoxicity. J Neurosci 2004;24: 1280-1287.

23 Lee J, Sung YH, Cheong C, Choi YS, Jeon HK, et al: TERT promotes cellular and organismal survival independently of telomerase activity. Oncogene 2008;27:3754-3760.

-24 Park JI, Venteicher AS, Hong JY, Choi J, Jun S, et al: Telomerase modulates Wnt signalling by association with target gene chromatin. Nature 2009;460:66-72.

25 Jurk D, Wang C, Miwa S, Maddick M, Korolchuk V, et al: Postmitotic neurons develop a p21-dependent senescence-like phenotype driven by a DNA damage response. Aging Cell 2012;11:996-1004.

26 Li J, Qu Y, Chen D, Zhang L, Zhao F, et al: The neuroprotective role and mechanisms of TERT in neurons with oxygen-glucose deprivation. Neuroscience 2013;252:346-358.

27 Iannilli F, Zalfa F, Gartner A, Bagni C, Dotti CG: Cytoplasmic TERT Associates to RNA granules in fully mature neurons: role in the translational control of the cell cycle inhibitor p15INK4B. PLoS One 2013;8:e66602.

28 Fauce SR, Jamieson BD, Chin AC, Mitsuyasu RT, Parish ST, et al: Telomerase-based pharmacologic enhancement of antiviral function of human CD8+ T lymphocytes. J Immunol 2008;181:7400-7406.

29 Zhu J, Lee S, Ho MK, Hu Y, Pang H, et al: In vitro intestinal absorption and first-pass intestinal and hepatic metabolism of cycloastragenol, a potent small molecule telomerase activator. Drug Metab Pharmacokinet 2010;25:477-486.

-30 Yung LY, Lam WS, Ho MK, Hu Y, Ip FC, et al: Astragaloside IV and cycloastragenol stimulate the phosphorylation of extracellular signal-regulated protein kinase in multiple cell types. Planta Med 2012;78:115-121.

31 Imomnazarov BA, Isaev MI: Triterpene glycosides of astragalus and their genins XXXVI. Cycloartanes of Astragalus uninodus. Chem Nat Comp 2004;27:381.

-32 Fathiazad F, Khosropanah MK, Movafeghi A: Cycloartane-type glycosides from the roots of Astragalus caspicus Bieb. Nat Prod Res 2010;24:1069-1078.

33 Wang P, Jou S, Chen W, Lee S: An improved oxidative cleavage method for large scale preparation of some acid-labile aglycones form glycosides. J Chin Chem Soc 2002;49:103-106.

-34 Ng YP, Wu Z, Wise H, Tsim KW, Wong YH, et al: Differential and synergistic effect of nerve growth factor and cAMP on the regulation of early response genes during neuronal differentiation. Neurosignals 2009;17:111120. 
Ip et al.: Cycloastragenol Is a Potent Telomerase Activator in Neuronal Cells: Implications for Depression Management

35 Fu WY, Chen Y, Sahin M, Zhao XS, Shi L, et al: Cdk5 regulates EphA4-mediated dendritic spine retraction through an ephexin1-dependent mechanism. Nat Neurosci 2007;10:67-76.

-36 Ip FC, Glass DG, Gies DR, Cheung J, Lai KO, et al: Cloning and characterization of muscle-specific kinase in chicken. Mol Cell Neurosci 2000;16:661-773.

-37 Porsolt R, Bertin A, Jalfre M: Behavioural despair in mice: a primary screening test for antidepressants. Arch Int Pharmacodyn Ther 1997;229:327-336.

38 Kulkarni SK, Mehta AK: Purine nucleoside-mediated immobility in mice: reversal by antidepressants. Psychopharmacology 1985;85:460-463.

-39 Ma XC, Dang YH, Jia M, Ma R, Wang F, et al: Long-lasting antidepressant action of ketamine, but not glycogen synthase kinase-3 inhibitor SB216763, in the chronic mild stress model of mice. PLoS One 2013;8:e56053.

$\checkmark 40$ Nibuya M, Nestler EJ, Duman RS: Chronic antidepressant administration increases the expression of cAMP response element binding protein (CREB) in rat hippocampus. J Neurosci 1996;16:2365-2372.

-41 Chen AC, Shirayama Y, Shin KH, Neve RL, Duman RS: Expression of the cAMP response element binding protein (CREB) in hippocampus produces an antidepressant effect. Biol Psychiatry 2001;49:753-762.

42 Gass P, Riva MA: CREB, neurogenesis and depression. Bioessays 2007;29:957-961.

$\checkmark 43$ Benito E, Barco A: CREB's control of intrinsic and synaptic plasticity: implications for CREB-dependent memory models. Trends Neurosci 2010;33:230-240.

44 Sheng M, Thompson MA, Greenberg ME: CREB: a Ca(2+)-regulated transcription factor phosphorylated by calmodulin-dependent kinases. Science 1991;252:1427-1430.

45 Mayr B, Montminy M: Transcriptional regulation by the phosphorylation-dependent factor CREB. Nat Rev Mol Cell Biol 2001;2:599-609.

46 Szabo NJ: Dietary safety of cycloastragenol from Astragalus spp.: subchronic toxicity and genotoxicity studies. Food Chem Toxicol 2014;64:322-334.

$\checkmark 47$ de Jesus BB, Schneeberger K, Vera E, Tejera A, Harley CB, et al: The telomerase activator TA-65 elongates short telomeres and increases health span of adult/old mice without increasing cancer incidence. Aging Cell 2011; 10:604-621.

48 Harley CB, Liu W, Blasco M, Vera E, Andrews WH, et al: A natural product telomerase activator as part of a health maintenance program. Rejuvenation Res 2011;14:45-56.

49 Boukamp P: Skin aging: a role for telomerase and telomere dynamics? Curr Mol Med 2005;5:171-177.

50 Menke NB, Ward KR, Witten TM, Bonchev DG, Diegelmann RF: Impaired wound healing. Clin Dermatol 2007; 25:19-25.

51 Sevimli-Gür C, Onbaşılar I, Atilla P, Genç R, Cakar N, et al: In vitro growth stimulatory and in vivo wound healing studies on cycloartane-type saponins of Astragalus genus. J Ethnopharmacol 2011;34:844-850.

52 Malberg JE, Schechter LE: Increasing hippocampal neurogenesis: a novel mechanism for antidepressant drugs. Curr Pharm Des 2005;11:145-155.

53 Perera TD, Coplan JD, Lisanby SH, Lipira CM, Arif M, et al: Antidepressant-induced neurogenesis in the hippocampus of adult nonhuman primates. J Neurosci 2007;27:4894-4901.

54 Eisch AJ, Petrik D: Depression and hippocampal neurogenesis: a road to remission? Science 2012;338:72-75. Castrén E, Rantamäki T: The role of BDNF and its receptors in depression and antidepressant drug action: reactivation of developmental plasticity. Dev Neurobiol 2010;70:289-297.

56 Diniz BS, Teixeira AL, Machado-Vieira R, Talib LL, Gattaz WF, et al: Reduced serum nerve growth factor in patients with late-life depression. Am J Geriatr Psychiatry 2013;21:493-496.

57 Del Bufalo D, Rizzo A, Trisciuoglio D, Cardinali G, Torrisi MR, et al: Involvement of hTERT in apoptosis induced by interference with Bcl-2 expression and function. Cell Death Differ 2005;12:1429-1438.

58 Massard C, Zermati Y, Pauleau AL, Larochette N, Metivier D, et al: HTERT: a novel endogenous inhibitor of the mitochondrial cell death pathway. Oncogene 2006;25:4505-4514. 